\title{
Breaking through Clutter: Analysis of Mobile Political Advertising in Malaysia
}

\author{
Azizul Yadi Yaakop, Siti Aishah Ismail, and Zailin Zainal Ariffin
}

\begin{abstract}
Political advertising is a type of marketing communication that attempts to influence upon issues of extensive political debate. In the era of IR 4.0, the platforms used to communicate political issues vary ranging from conventional media to new online media like social media and mobile advertising apps. During the past a few general elections in Malaysia, public witnessed changes in political campaigns with the use of advertisements not only on the mainstream television and in the newspapers, but also in other forms of online media. With the arrival of these modern-day advertising media, the role of political campaigners has becoming more challenging than ever. In the recent 2018 14th General Election the use of the mobile advertising platform was seen as dominant. This study was conducted to investigate voters' advertising perceptions and attitudes toward political advertising in Malaysia, delivered mobile advertising platform (WhatsApp). The study confirms that attitudes toward political advertising can only be predicted by product information function for the media under study. The implications of the study focus on consumers' perceptual shift in terms of the relevance of mobile app (WhatsApp) in propagating political parties in Malaysia, hence breaking through the advertising clutter. The limitations of the study are also discussed.
\end{abstract}

Index Terms-Political advertising, attitudes towards advertising, mobile advertising, SMART-PLS.

\section{INTRODUCTION}

There is an abundance of literature on attitudes toward advertising in various consumerism, marketing and advertising journals as it is a popular subject to study in relation to a specific group of consumers. The studies, among others, include consumers' attitudes towards certain attributes of advertisement as well as specific advertising media or platforms.

The findings may have resulted in outcomes that predict advertising effectiveness, brand attitudes and purchase intention. For instance, [1] examined cross-cultural perspective on outdoor advertising and its effect in the modern era. [2] investigated brand placements in in-gameadvertising and in-app-advertising which are predicted to tremendously affect revenue of the digital game industry. In Malaysia, consumers' perception towards online advertising was examined recently by [3]. There are also studies on advertisements that are specifically targeted at certain

Manuscript received February 12, 2019; revised April 12, 2019.

Azizul Yadi Yaakop and Siti Aishah Ismail are with the Universiti Malaysia Terengganu 21030 Kuala Nerus, Terengganu, Malaysia (e-mail: azizul_yadi@umt.edu.my,sa_aishah@yahoo.com.my).

Zailin Zainal Ariffin is with the National Defence University of Malaysia, 57000 Sungai Besi, Kuala Lumpur, Malaysia (e-mail: zailin@upnm.edu.my). audiences such as children, ethnicity and special target groups. For our current discussion in the perspective of political advertising, [4] investigated the use of mainstream media in the midst of the presence of modern day media and they found that mainstream media play a crucial role as the main political information source for voters. This is the issue in hand, does social media and the likes have it place in political advertising in the era of industrial revolution 4.0?

Political advertising is advertising that attempts to influence upon a matter of extensive political debate. It includes advertising or marketing communication with community about a political party representative or candidate, advertising about political issue or issue of public interest and advertising in relation to government political. In spite of "no rule" ruling to the content and form of political advertising, it has become increasingly essential to campaign strategy. As a matter of fact, the current state of political advertising has been considered within the world of commercial advertising [5]. Political advertising does not exist occasionally, the presence is apparently ubiquitous. Similar to other parts of the world, political advertising is more prevalent during the elections in Malaysia's political scene. According to [6], mass media has an important role to affect the voters' decision to vote due to its informative role. Media is also of paramount important to inform voters about candidates' positions and affecting the 'preferences and participatory ethos of the electorate [7].

At this point, a preliminary question need to be answered what kind of roles do modern-day media play in propagating political issues? Therefore, in this study, we are interested to understand Malaysian voters' perceptions and attitudes towards political advertising in the era of IR 4.0 specifically delivered through mobile app platform (WhatsApp).

In Malaysia's political scene, political advertising have been practiced since the 1960's. In 1969 election, the use of printed media such as national newspapers to disseminate information to voters was crucial [8]. Nowadays, public witness changes in political campaigns when political advertisements appeared not only on newspapers and the television, but in many forms of modern-day media. Likewise, the contemporary political campaigns in Malaysia now have evolved dramatically from mainly relying on using traditional media including mainstream media (electronic and printed), video tapes, banners and flyers to advertise their agenda to using the Internet. To the practitioners, this demonstrates how mass media plays an important role in changing political landscape in Malaysia. However, from the voters' perspective, do they think political advertising in these media has the role to winning any political election? This is the question that needs answers prior jumping into any bandwagon. 
Broadly, the focus of this research is to understand the perceptions of voters of the various use of media for political advertising and to investigate how they relate to the respondents' overall attitude towards political advertising. This will involve testing a set of predictive variables in relation to the attitude of political advertising, by identifying and comparing the factors that influence consumer attitudes toward political advertising measured through the variables of advertising perceptions of product information (PI), hedonic / pleasure (HP), social role (SR) and falsity/no sense (FN) during the 14th General Election.

\section{Political AdVertising on Mobile ApP}

Although the internet is relatively new, this technology is enriching people's lives. The Internet and smartphones for that matter, bring something new to the politics. With the omnipresence of the social media and the likes, technologies evolve. Now, voters are getting personalised information instantly by chatting. This services from companies like WhatsApp, WeChat and Snapchat and Telegram have raised the bar for voter's experience. To some, this may be viewed as technology extending old politics. Others may view this as a new paradigm, where information is available, greater transparency is unavoidable leading to new institutions arise replacing the old [9]. According to [9], the technology like mobile advertising has enabled voters to see changes in political scenario by allowing opportunities for people to build reciprocity and trust and creating community and social capital for collective action.

The idea of using mobile app such as WhatsApp and Telegram to disseminate information of political content is related to the capability of these platforms to facilitate wordof-mouth (eWOM) among established social communities. In consistency with the topic of trust in the online environment as mentioned earlier, the use of mobile app will provide a potential avenue for political campaigners to counter the problem of voters' lack of trust in political issues raised, hence creating mutual enlightenment in public opinion. [10] discovered that trust is one of the social relationship constructs that has a positive and significant impact on eWOM in online environment. They opined that eWOM behaviour has increased in SNS due to users' willingness to rely on their social connections on the 'friends' list. With this matter in mind, it is therefore predicted that:

$\mathrm{H}_{1}$ : Product information role of advertising significantly predict Malaysia voters' attitudes towards political advertising on WhatsApp

$\mathrm{H}_{2}$ : Hedonic/pleasure role of advertising significantly predicts Malaysia voters' attitudes towards political advertising on WhatsApp

$\mathrm{H}_{3}$ : Social role of advertising significantly predict Malaysia voters' attitudes towards political advertising on WhatsApp

$\mathrm{H}_{4}$ : Falsity/no sense role of advertising significant predicts Malaysia voters' attitudes towards political advertising on WhatsApp.

\section{RESEARCH METHODOLOGY}

This study aims to examine the perceptions and attitudes of Malaysian voters' towards political advertising delivered through two different media on Facebook and WhatsApp. The questionnaire of the study consists of five sections. The first section is about measuring respondents' perceptions towards political advertising on the television, printed media and the social media. The next three sections are about measuring respondents' attitudes towards political advertising on Facebook and WhatsApp, respectively. The final section consists of multiple questions regarding respondents' demographic profile.

In section one, two constructs were developed to measure political advertising perceptions using 5 items for each construct on a 5-point Likert scale (e.g. 1 - strongly agree to 5 - strongly disagree). The variables used were product information (PI); to measure individual's beliefs about advertising as a valuable source of information for products or services. Secondly, hedonic/pleasure (HP); a variable that encompasses individual's beliefs about advertising in terms of it being entertaining, amusing and pleasurable.

Meanwhile, in the section of measuring political advertising attitudes, three items were measured the construct. The items of measuring attitudes using semantic differential scales with 7-point scale (e.g. 1 - good to 7 - not good). All the items in the questionnaire were developed based on [11] and [12].

The data collection was conducted via Google Forms and it was carried out for a period of one month following the dissolution of the Malaysian Parliament on 7th April 2018. During this period, the campaigns from political parties participated were very aggressive and the use of the media was employed to reach the audience. The survey was posted in the Facebook as well as disseminated via multiple WhatsApp groups. All information provided by respondents was kept confidential. A total of 269 useable set of questionnaires were collected and all data collected went through a series of analyses by using SMART-PLS.

\section{ANALYSIS AND FINDINGS}

\section{A. Respondent Profile}

Based on the Table I, participation from male respondents were higher than female respondents which contribute to 63 percent and 37 percent, respectively. Malay ethnic contributes to the highest ethnic composition in Malaysia to participate ( 82 percent), followed by Indian ( 8 percent) and Chinese and Bumiputra with percentage of 6 percent and 4 percent, respectively. Respondents live in city were with the highest participation 52 percent compared to rural and suburban area, 25 percent and 23 percent respectively.

\section{B. Measurement Model}

Measurement model is also known as outer model in PLSSEM. They are used to establish latent variables by certain indicator variables. There are two types of measurement models, which are reflective measurement models and formative measurement models. A reflective measurement model has relation from the latent variable to its indicators. In contrast, formative measurement model has relation from the indicators to the latent variables [13]. This paper uses the reflective measurement models. 
TABLE I: RESPONDENT PROFILE

\begin{tabular}{|l|c|c|}
\hline \multicolumn{1}{|c|}{ Category } & Frequency & Percentage of total \\
\hline Sex (N =269) & 170 & 63.2 \\
Male & 99 & 36.8 \\
Female & & \\
Ethicity (N = 269) & 220 & 81.8 \\
Malay & 16 & 5.9 \\
Chinese & 21 & 7.8 \\
Indian & 12 & 4.5 \\
Other Bumiputra & & \\
Residential are (N = 269) & 141 & 52.4 \\
City area & 62 & 23.0 \\
Surburban residential & 66 & 24.6 \\
Rural area (village) & \multicolumn{2}{|l}{} \\
\hline
\end{tabular}

TABLE II: RESUlt SUMMARY FOR REFLECTIVE MEASUREMENT MODEL (WHATSAPP)

\begin{tabular}{|c|c|c|c|c|c|}
\hline Construct & Items & Loading & CR & AVE & Decision \\
\hline \multirow{2}{*}{$\begin{array}{l}\text { Attitude } \\
\text { (ATT) }\end{array}$} & AW1 & 0.881 & \multirow{2}{*}{0.87} & \multirow{2}{*}{0.771} & \multirow{2}{*}{ Supported } \\
\hline & AW3 & 0.876 & & & \\
\hline \multirow{3}{*}{$\begin{array}{l}\text { Falsity No } \\
\text { Sense (FNS) }\end{array}$} & FN2W & 0.784 & \multirow{3}{*}{0.75} & \multirow{3}{*}{0.515} & \multirow{3}{*}{ Supported } \\
\hline & FN4W & 0.829 & & & \\
\hline & FN5W & 0.494 & & & \\
\hline \multirow{5}{*}{$\begin{array}{l}\text { Hedonic } \\
\text { Pleasure (HP) }\end{array}$} & HP1W & 0.880 & \multirow{5}{*}{0.91} & \multirow{5}{*}{0.668} & \multirow{5}{*}{ Supported } \\
\hline & HP2W & 0.852 & & & \\
\hline & HP3W & 0.786 & & & \\
\hline & HP4W & 0.803 & & & \\
\hline & HP5W & 0.760 & & & \\
\hline \multirow{5}{*}{$\begin{array}{l}\text { Product } \\
\text { Information } \\
\text { (PI) }\end{array}$} & PI1W & 0.844 & \multirow{5}{*}{0.91} & \multirow{5}{*}{0.667} & \multirow{5}{*}{ Supported } \\
\hline & PI2W & 0.857 & & & \\
\hline & PI3W & 0.841 & & & \\
\hline & PI4W & 0.742 & & & \\
\hline & PI5W & 0.794 & & & \\
\hline \multirow{4}{*}{$\begin{array}{l}\text { Social Role } \\
\text { (SR) }\end{array}$} & SR1W & 0.789 & \multirow{4}{*}{0.90} & \multirow{4}{*}{0.684} & \multirow{4}{*}{ Supported } \\
\hline & SR2W & 0.809 & & & \\
\hline & SR3W & 0.872 & & & \\
\hline & SR4W & 0.836 & & & \\
\hline
\end{tabular}

There are several steps to assess the reliability and validity of the construct measure. They are Internal Consistency, Indicator Reliability, Convergent Validity and Discriminant Validity. After the reliability and validity are established, the structural model can then be examined [13]. The composite reliability (CR) is a method to assess for internal consistency. According to [13] the composite reliability should be higher than 0.70 . According to Table 5.2, the value of construct range between 0.753 until 0.909 .

Indicator reliability results from the outer loading of each individual indicator (items). The high values of the loading indicate that the indicators are dominated by the construct [13]. Next, the loading for reflective measure should be interpreted. The measurement model is suitable with the path model since the loading for the items ranged from 0.494 to 0.881 . The value of loading meets with the suggested value loading of 0.70 . Otherwise, loading between 0.40 and 0.70 can be deducted if CR and AVE did not meet the suggested value [13]. Convergent validity is used to find out if the measure positively correlates with the same construct [13]. Outer loadings are expected to access the convergent validity (AVE) in the reflective measurement model. High values of the loading indicate that the indicators are dominated by the construct. Hair et al. (2013) described AVE as the squared of mean value of loading of indicators. Hair et al. $(2011,2014)$ suggest the value of AVE should be more than 0.50 , which means that the variance that explains the construct is more than half. Table shows that the value of AVE is more than the suggested value, the range was from 0.515 to 0.771 .

Discriminant validity is carried out to determine whether the constructs differ from other constructs. This means that the constructs are single and do not signify with other constructs in the model [13]. There are two approaches to assess the discriminant validity, namely the Fornell-Larcker criterion and cross loading of items [13]. According to [13], Fornell-Larcker criterion is achieved when the AVE of each construct is square rooted. Table shows that the squared root of AVE for each construct was higher than other intercorrelations of the latent constructs (see text in bold).

TABLE III: FORNELL-LARCKER CRITERION (WHATSAPP)

\begin{tabular}{|l|l|l|l|l|l|}
\hline \multicolumn{1}{|c|}{ Construct } & ATT & FNS & HP & PI & SR \\
\hline Attitude & $\mathbf{0 . 8 7 8}$ & & & & \\
\hline $\begin{array}{l}\text { Falsity No } \\
\text { Sense }\end{array}$ & 0.440 & $\mathbf{0 . 7 1 8}$ & & & \\
\hline $\begin{array}{l}\text { Hedonic } \\
\text { Pleasure }\end{array}$ & 0.455 & 0.609 & $\mathbf{0 . 8 1 7}$ & & \\
\hline $\begin{array}{l}\text { Product } \\
\text { Information }\end{array}$ & 0.545 & 0.705 & 0.781 & $\mathbf{0 . 8 1 7}$ & \\
\hline Social Role & 0.516 & 0.695 & 0.770 & 0.876 & $\mathbf{0 . 8 2 7}$ \\
\hline
\end{tabular}

Discriminant validity is constant when outer loading for indicator loading on a construct is more than all its loadings with other constructs [13]. All the indicator loadings were higher than indicator loadings with other constructs.

\section{Structural Model}

TABLE IV: PATH COEFFICIENTS (WHATSAPP)

\begin{tabular}{|c|c|c|c|c|c|}
\hline $\begin{array}{l}\text { Hypoth } \\
\text { esis }\end{array}$ & $\begin{array}{l}\text { Orig. } \\
\text { Sample }\end{array}$ & $\begin{array}{l}\text { Stand. } \\
\text { Dev. }\end{array}$ & T Stats & $\begin{array}{l}\mathrm{P} \\
\text { Val. }\end{array}$ & Decision \\
\hline $\begin{array}{l}\text { FNS -> } \\
\text { ATT }\end{array}$ & 0.088 & 0.073 & 1.202 & 0.23 & $\begin{array}{l}\text { Not } \\
\text { Supported }\end{array}$ \\
\hline $\begin{array}{l}\text { HP } \quad-> \\
\text { ATT }\end{array}$ & 0.036 & 0.101 & 0.356 & 0.72 & $\begin{array}{l}\text { Not } \\
\text { Supported }\end{array}$ \\
\hline $\begin{array}{l}\text { PI }{ }^{->} \\
\text {ATT }^{->}\end{array}$ & 0.348 & 0.140 & 2.489 & 0.01 & Supported \\
\hline $\begin{array}{l}\text { SR } \quad-> \\
\text { ATT }\end{array}$ & 0.122 & 0.131 & 0.933 & 0.35 & $\begin{array}{l}\text { Not } \\
\text { Supported }\end{array}$ \\
\hline
\end{tabular}

According to [13], the indicators of significant value are $p<0.01$ (2.33) and $p<0.05$ (1.645). Table confirmed that hypothesis 3 were significant with attitude at significant 
indicators of $p<0.01$. Specifically, hypothesis 1,2 and 4 was not-significant because the significant value was more than 0.05 .

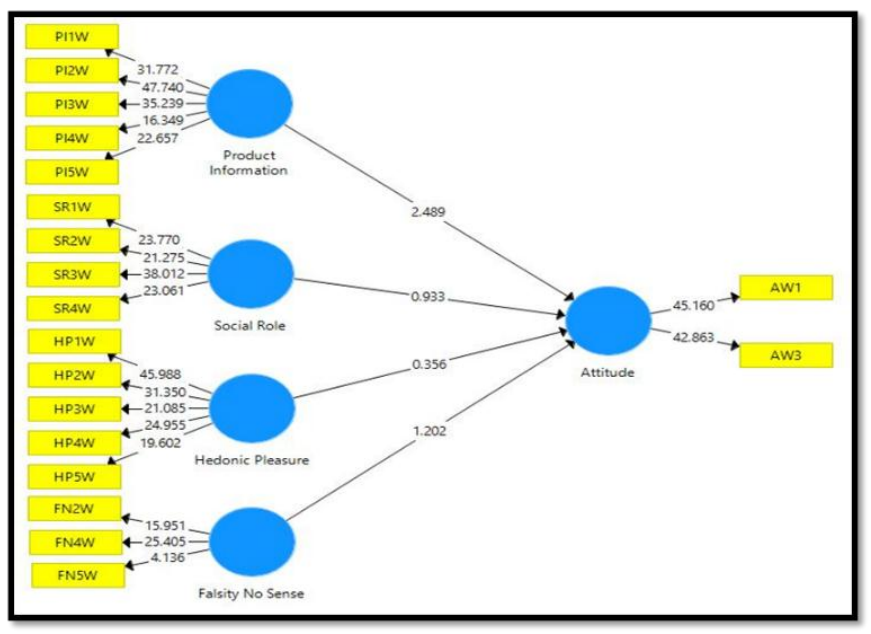

Fig. 1. Structural model (Whatsapp).

\section{DISCUSSION}

SMART-PLS results had partially supported the hypotheses; to our surprise, political adverting on modern media is favoured because of its informative nature, which was not the case in the previous 13th General Election. A possible reason behind this was - the nature of voters in this round of general election. Young voters made up of 34 percent of the total population and the voice of this group are key for Malaysia election win. Young Malaysians voters are, apparently, increasingly depending on the new media for news. For this specific reason, many political parties' campaigners tried to control narratives and dominate social media and the likes by creating online groups to shower constituents with messages. This is in line with the results by [14] that investigated the use of interactive digital marketing campaign especially to young voters which is very much relevant to the current scenario. All other three variables especially hedonic pleasure (which was significant in the previous study) and social role have no significant influence at all on Malaysian voters' attitudes towards political advertising on WhatsApp.

It is, in fact, interesting to understand that the mobile app platform are example of medium of sharing information not simply for the sake of its social role and amusement function. Voters feel that the news or propaganda they receive and read on the modern media are believable and not just information that entertain them. In politics, voters are now more knowledgeable to distinguish between facts and rumours communicated through the social media and the likes. For this reason, campaigners strategized to have targeted micro-campaigns which allows them to tailor messages direct to individual voters. To optimize the impact, political parties pay social media firms to send constituents these messages directly into their main inboxes, ensuring maximum media reach. It is important to note that news, regardless if they were factual or fiction, news presented especially in the social media and mobile app platforms during a month before the 14th General Election were substantial. In the most crucial time just a month before the election, some campaigners were seen to fully utilize the media by propagating rumours to create panic given the time constraint. Even this instance happened, it probably has no effect to the voters' doubts about the social media and mobile app platforms.

\section{LIMITATIONS AND FUTURE RESEARCH}

As mentioned earlier, researchers who used limited-parent population could only justify the dimensions explaining the research framework without generalizing the findings and drawing conclusions about the overall public attitude towards political advertising. In this particular study, any conclusion drawn from this limited-parent population sample (Malaysian voters) would be misleading because the sample basis does not represent the total population despite the justifications as mentioned above. The findings represent responses from respondents' perceptions from a sufficiently diverse background, however collected from a short period of time (one month period). Future research may consider using a more general and representative population of voters (i.e. raising the sample size).

\section{CONCLUSION AN IMPLICATION}

Ref. [15] opined that issues in vast areas of advertising must be tackled with a deeper understanding of consumers' relationships with advertising and the media. This present study fully supports this notion and, in addition, has discovered that any generic issues, such as what were uncovered in this study, must be seen from a specific media frame of reference (i.e. the tradional media and the modern media). In this study, advertising perceptions such as product information has great effects on the attitudes towards political advertising delivered through the modernday media like Facebook and WhatsApp. From the findings of this research, the political parties, campaigners and advertising practitioners need to understand and pay more attention on how the consumers, especially young voters perceive the function of these advertising media when making decisions, especially in the selection of media to propagate political issues, before jumping on the social media bandwagon.

\section{REFERENCES}

[1] M. S. Fung, "An IMB model testing via endorser types and advertising appeals on young people's attitude towards cervical cancer prevention advertisement in Hong Kong," Young Consumers, vol. 18, no. 1, pp. 1-18, 2017.

[2] S. Bidmon and J. Röttl, "Advertising effects of in-game-advertising vs. in-app-advertising," Advances in Advertising Research IX, pp. 73-86, Springer Gabler, Wiesbaden, 2018.

[3] F. C. Haur, A. Khatibi, and S. F. Azam, "Antecedents of Consumers'perception towards online advertising in Malaysia: The structure equation modeling approach," European Journal of Management and Marketing Studies, 2017.

[4] A. Salman, M. A. M. Salleh, M. Y. H. Abdullah, N. Mustaffa, A. L. Ahmad, C. P. Kee, and S. Saad, "ICT acceptance among Malaysian urbanites: A study of additional variables in user acceptance of the new media," Geografia-Malaysian Journal of Society and Space, vol. 10, no. 6, 2017.

[5] D. W. Greening and B. Gray, "Testing a model of organizational response to social and political issues," Academy of Management Journal, vol. 37, no. 3, pp. 467-498, 1994. 
[6] K. H. Jamieson and K. K. Campbell, The Interplay of Influence: News, Advertising, Politics, and the Mass Media, 2000.

[7] S. Ansolabehere and S. Iyengar, Going Negative: How Political Advertisements Shrink and Polarize the Electorate, New York: Free Press, 1995.

[8] K. J. Ratnam and R. S. Milne, "The 1969 parliamentary election in west malaysia," Pacific Affairs, vol. 43, no. 2, pp. 203-226, 1970.

[9] I. S. Wu, Forging trust Communities: How Technology Changes Politics, JHU Press, 2015.

[10] S. C. Chu and Y. Kim, "Determinants of consumer engagement in electronic word-of-mouth (eWOM) in social networking sites," International journal of Advertising, vol. 30, no. 1, pp. 47-75, 2011.

[11] D. Petrovici and M. Marinov, "Determinants and antecedents of general attitudes towards advertising," European Journal of Marketing, vol. 41, no. 3/4, pp. 307-326, 2007.

[12] A. Y. Yaakop, M. M. Anuar, and K. Omar, "Like it or not: Issue or credibility in Facebook advertising," Asian Social Science, vol. 9, no. 3, pp. 154-163, 2003.

[13] J. F. Hair, C. M. Ringle, and M. Sarstedt, "Partial least squares structural equation modeling: Rigorous applications, better results and higher acceptance," 2013.

[14] M. Leppäniemi, H. Karjaluoto, H. Lehto, and A. Goman, "Targeting young voters in a political campaign: Empirical insights into an interactive digital marketing campaign in the 2007 Finnish general election," Journal of Nonprofit and Public Sector Marketing, vol. 22, no. 1, pp. 14-37, 2010.
[15] E. C. Hirschman and C. J. Thompson, "Why media matter: Toward a richer understanding of consumer' relationships with advertising and mass media," Journal of Advertising, vol. 26, no. 1, pp. 43-60, 1997.

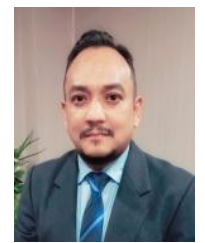

Azizul Yadi Yaakop is an associate professor at School of Maritime Business and Management, Universiti Malaysia Terengganu (UMT), Malaysia Prior to his appointment at UMT, Azizul served International Islamic University Malaysia (IIUM) in a different capacity.

Azizul holds a $\mathrm{PhD}$ in marketing obtained from University of Surrey, United Kingdom in 2011 with his $\mathrm{PhD}$ study titled "Tourists' attitudes towards advertising in a Malaysian tourism context," His research interests are in the field of consumer behaviour (including tourist Behaviour) and marketing communication (especially in advertising attitudes and social media studies). He has been leading some projects funded by the Malaysian government for the past 10 years in the areas especially related to scholarship of teaching and learning - technology acceptance in pedagogical practices across the tertiary sector and advertising effectiveness in Malaysian higher education institutions (HEIs). Some recent research projects related to HEIs are adoption of Web 2.0 interactive edutools in Malaysia and university brand identification Other researches related to social media studies are social media and mobile political advertising in the era of IR 4.0. 